\title{
Exploring the Underlying Factors in Learning Assistant - Faculty Partnerships
}

\author{
Felicia Davenport, Fidel Amezcua, Mel S. Sabella, and Andrea G. Van Duzor \\ Department of Chemistry, Physics, and Engineering Studies, Chicago State University, \\ 9501 S. King Drive, Chicago, IL, 60628
}

\begin{abstract}
An effective Learning Assistant (LA) Program provides benefits for both Learning Assistants (LAs) and faculty, in addition to benefits for students. By analyzing LA and faculty reflections, weekly preparation sessions, and interviews with LAs and faculty, we can better understand the partnerships that develop between faculty and their LAs. We leverage a combination of qualitative and quantitative data to investigate the types of LA expertise and skills faculty value and how this affects the formation of these partnerships. The Preparation Session Observation Tool (PSOT), developed from this work, can be used by LAs, LA Program Coordinators, and faculty to reflect on the types of LA partnerships that emerge, and how these partnerships can be used in constructing effective learning environments. We anticipate that this tool can then be used to help LAs, coordinators, and faculty modify their working relationship to develop the type of partnerships that are best for their particular instructional setting. PSOT provides a finer-grained analysis to three broad partnership classifications that exist along a continuum: mentor-mentee, facultydriven collaboration, and collaborative.
\end{abstract}

\section{INTRODUCTION}

The Learning Assistant (LA) Model leverages the expertise of students (LAs) to work as facilitators of learning in the classroom [1]. This model, developed at the University of Colorado-Boulder, with implementation at over seventy institutions around the country, involves extensive support for LAs in the form of weekly preparation and pedagogy sessions [2].

While pedagogy courses in LA Programs are typically well defined and structured, weekly preparation sessions tend to have little structure with great variation in the way they are conducted both across institutions and within institutions[3,4]. In our previous work we highlighted different types of partnerships that form between LAs and their respective faculty members. These different types, mentor-mentee, faculty-driven collaboration, and collaborative, exist along a continuum and are summarized below [5].

- Mentor - Mentee: One-directional with limited LA input on classroom dynamics and reflection on student understanding;

- Faculty driven collaboration: Faculty elicit feedback from LAs and guide how LAs will be involved in the course; LAs do not co-design instructional materials;

- Collaboration: Faculty elicit feedback and then, with their LA, co-design and co-implement instructional materials;

The structure of these partnerships is best observed during the weekly preparation session where instructors and their respective LAs meet to discuss the course, course content, student understanding, course activities, and instructional delivery. At some institutions with large LA Programs, weekly preparation sessions may be run by coordinators with LAs from multiple sections of a course potentially with multiple instructors. However, in this work we focus on smaller LA Program dynamics where instructors for specific courses lead the weekly preparation sessions. These sessions are specific to the course as the instructor prepares the LAs for the delivery of upcoming material and assignments and, in some cases, both LA and instructor reflect on previous in-class situations. For instance, the LA and instructor might discuss how certain topics were explained and highlight what methods did and did not aid the students' comprehension. The instructor or LA may present new ideas on activities to help the students better grasp ideas or allow the LA to revisit the material to solidify their understanding. The dynamics of these sessions vary from instructor to instructor.

This preliminary work describes our efforts in developing an analysis tool to allow LAs, LA Program Coordinators, faculty, and researchers to reflect on, and modify, their weekly preparation sessions. The tool allows us to describe the three broad categories, summarized earlier, and provides a finer-grained analysis. We believe that our tool, which we refer to as the Preparation Session Observational Tool (PSOT), provides useful information about the weekly sessions as well as a scaffold for instructors and LAs to include specific activities in these sessions to develop LA-faculty partnerships that benefit diverse learning environments in multiple disciplines.

The PSOT can be used for researchers, faculty and LAs who want to conduct a deep analysis of weekly interactions and partnerships or with those who want to get a quick view of the type of LA-faculty partnership they have. LA Program directors or coordinators could use the PSOT as another level of assessment in their LA Program to complement the use of diagnostics and other measures. Analysis of PSOT data can also be used by directors and 
coordinators to develop and implement targeted professional development in their programs. We present the initial version of PSOT and present transcripts from video analysis of weekly preparation sessions to focus on and illustrate how four of the seven codes from PSOT are determined.

\section{BACKGROUND}

\section{A. Factors affecting partnerships and weekly preparation sessions}

In previous work we highlighted a number of factors that affected the types of partnerships that form between LAs and faculty. For instance, if an LA required additional content understanding, faculty needed to spend more time on content preparation, often resulting in a more one-sided partnership (mentor-mentee). If instructional materials are well established there may be fewer opportunities for collaboration between the LAs and faculty. If an instructor wanted to develop sets of inquiry activities for a new course, this might involve a more collaborative partnership. The development of particular partnerships also depends on how faculty and LAs viewed their roles [5]. For instance, does an instructor view the LA as a co-thinker in instruction reform and provide a space that welcomes co-thinking? While each of these partnership types have a place in the LA Model it is important to reflect on, and recognize why a particular partnership type serves a specific need. Although mentor-mentee relationships are sometimes the most appropriate, truly collaborative relationships between an LA and a faculty member can provide an extremely rich set of resources for classroom instruction and provide unique opportunities for the LA and faculty member to develop additional skills, and enhance student learning.

\section{B. Overview of the PSOT}

The PSOT serves to document LA/instructor interactions during the LA Model's weekly preparation session in order to better understand the types of interactions in these sessions. The PSOT is used in a similar way to more established tools, such as the Classroom Observational Protocol for Undergraduate STEM (COPUS), in which behaviors are documented at two minute intervals.

The codes developed for PSOT are based on the interactions observed in the weekly sessions, on surveys, and on interview data with CSU LAs and faculty. There are two broad observation categories in the PSOT: Instructor to $L A$ and $L A$ to Instructor. The codes we identify here are preliminary but have gone through a number of iterations. Videos of weekly preparation sessions were analyzed multiple times by a single researcher and individual episodes were cross analyzed by multiple researchers. With each viewing, specific codes were revised, some were removed and other codes were added. Table 1 shows codes in PSOT with associated descriptions.

TABLE 1. Prep-session Observation Tool (PSOT) Codes and Descriptions

\begin{tabular}{|l|l|l|l|}
\hline LA to Instructor Codes & Instructor to LA Codes \\
\hline LCT(U,S) & $\begin{array}{l}\text { Content Talk: LA talks about } \\
\text { content and either demonstrates } \\
\text { understanding or seeks clarification } \\
\text { from Instructor (LCTU, LCTS). }\end{array}$ & IT(GI, L) & $\begin{array}{l}\text { Teaching: Instructor guides LA through course content } \\
\text { by modeling inquiry teaching or through lecture } \\
\text { instruction (ITGI or ITL). }\end{array}$ \\
\hline LR & $\begin{array}{l}\text { LA Reflection: LA reflects on students' } \\
\text { understanding/resources/difficulties/etc. }\end{array}$ & IR & $\begin{array}{l}\text { Instructor Reflection: Instructor reflects on students' } \\
\text { understanding/resources/difficulties/etc. }\end{array}$ \\
\hline L-IM & $\begin{array}{l}\text { LA suggests an in-class modification: A } \\
\text { modification is suggested to the } \\
\text { instructor such as an activity for class } \\
\text { (i.e. a set of clicker questions, mini lab, } \\
\text { homework problems, exam questions). }\end{array}$ & $\begin{array}{l}\text { Instructor suggests an in-class modification: A } \\
\text { modification is suggested to the LA such as an activity } \\
\text { for class (i.e. a set of clicker questions, mini lab, } \\
\text { homework problems, exam questions) }\end{array}$ \\
\hline
\end{tabular}




\section{CONTEXT OF THE WORK}

Data for this study comes from videos of preparation sessions between LAs and faculty in general education (critical thinking in science), biology, chemistry, and physics classes at CSU. IRB protocols were followed and no names are presented here. All faculty involved have had prior experience with the LA Model. Some LAs are new to the program and others have had previous experience.

\section{DESCRIBING RUBRIC CODES WITH EXAMPLES}

To help the reader understand the PSOT, we present how video data from the session maps to four observational codes in PSOT. The examples come from a biochemistry course, although the specific discipline is not important to the analysis. Our data set did not include examples from the physics class that were as illustrative of the four categories we present, in part because our physics sequence uses well established curricula which tends to foster faculty driven collaborative partnerships.

The four categories we focus on were chosen because they provide examples of how valuing the expertise of LAs and creating environments that welcome collaboration can benefit our students and courses. These categories: $L A \&$ Instructor reflections on student learning and LA \& Instructor suggested in-class modifications are often characteristic of a more collaborative partnerships. In the transcripts presented, [...] indicates omission of text that does not change meaning and [-] indicates a pause.

\section{A. LA and Instructor reflections on learning (LR/IR)}

Reflecting on student learning is an essential piece of high quality instruction, as reflective practitioners continuously evaluate the effectiveness of instruction and try to determine students' levels of understanding. The preparation session provides an explicit space for the course instructor (I) and the LA to engage in this process. In this example the instructor asks for the LA's impressions of where students struggled. The following is a section of transcript that would be categorized as ( $L R / I R)$.

I: ...How did you handle that...?

LA: ...first I wanted to understand what they were processing as $k_{\text {cat }}$ and seconds... a lot of times when I am working with the students it's always good for me to understand...how they see the problem because even if I know the answer - if their train of thought is not quite aligned with mine then there is a disconnect...So... I'm like, okay, let me understand what you're understanding here and how you're setting it up...I was able to explain to them

- 'Okay, what does $k_{\text {cat }}$ mean?' And...as far back as numerator and denominator - 'Where would you think that [would] go?'... 'How would you work that out?' and that's when a lot of "a-ha" moments came ...

I: Okay...you're right...I was wondering how did you get through that. So that was good to know...so I think everybody did eventually get that.

This interaction involves both the LA and the faculty member reflecting on student learning and student understanding (LR: LA Reflection and IR: Instructor Reflection). Specifically, the instructor invites the LA to reflect on how the students in the class approached a particular question on enzyme reactions and invited the LA to think about where student confusion arose. The instructor is also interested in seeing how the LA handled the students' confusion. The LA explained how she helped the students in their process of understanding the question and identifying where they struggled $(L R)$. This led to the instructor acknowledging that the students were eventually figuring out the problem successfully (IR). With both the LA and the instructor reflecting on student learning in this context, the instructor learns more about where the students had difficulty from the LA's perspective and sees how the approach the LA took assisted the students.

\section{B. LA suggested in-class modification and instructor positive response (L-IM/IM-P)}

LAs can provide feedback based on a student's perspective both with regard to content learning and the climate of the course. Faculty mentors and LAs can act on this feedback to collaboratively make changes in the classroom to impact student understanding. As a way to reinforce understanding and to make the conceptual load of the activity more manageable, the LA, in this example, suggests an in-class modification to the course that the instructor decides to incorporate. The following is section of transcript that would be categorized as ( $L-I M / I M-P)$.

LA: I'm thinking even with glycolysis or the glucose in the entire processes...it makes we wonder if we can go through the top half of that, but I think once again that probably depends on the time that we are working with, so it won't seem...overwhelming...you know, all of these enzymes or all of this information...maybe we can do a, uh, small like miniquiz or recap prior...

I: Yes. OK - OK! (writes down on her notes)

LA:...that way it won't seem extremely heavy like 'oh my gosh we have to remember all of these different-you know, enzymes and'-

I: So a little, umm, mini-quiz?

LA: Yeah, I think that would be good ... just to kinda see ... what they should have harnessed...

I: You think they'll like that?

LA: I think so, because it gives them the opportunity to not only go through the information and process it but actually go home and study...to see how that's going to play intoyou know, learning the second half.

In this segment of the weekly preparation session, the LA presents an in-class modification (L-IM). Specifically, she introduces the idea of creating a quiz to refresh the 
students' memory and assess what they have retained from the material they've covered without guidance from the instructor. This is an activity that the instructor would most likely not have implemented if the LA had not suggested it. The instructor had a positive response (IM-P) to this suggestion and incorporated it into the course. The modification helped relieve some of the faculty's concerns regarding whether students were actually prepared since she had received little feedback from them.

\section{THE IMPORTANCE AND IMPACT OF WEEKLY PREPARATION SESSIONS}

The four PSOT categories we present are characteristic of more collaborative partnerships between LAs and faculty. Effective weekly preparation sessions are an essential piece to an effective LA Program and play a major role in creating effective learning environments. They indirectly affect students in LA supported classes and they directly affect how LAs develop identity as scientists and become part of the science education community [6].

In an interview with one of our LAs, who was able to contrast two different partnership experiences, she described the expertise of LAs and the importance of involving LAs in collaborative ways. She stated that: "... the relationship I would prefer is definitely the collaborative one...me and [my faculty mentor]...were always emailing back and forth...I was only assigned to her for like a week and I think I had spoken with her like five different times before class even started...that's definitely the relationship I would prefer...working in collaborative relationship." She then described how both LAs and faculty have diverse expertise and can learn from one another: "I get this feeling that I'm like way, way underneath...like my ideas are kind of out of place...professors...know way, way more than I do - but I know way, way more than they do about the students that they have - because like I'm experiencing it right now ...like I can learn a lot from you - but you can learn a lot from me...I'm going to help you out just as much as you help me out." Collaborative relationships can lead to mutual growth and development for LAs and faculty.

\section{CONCLUSIONS}

While this is preliminary work, we expect that in its current form the PSOT can be used by LAs, coordinators, instructors, and researchers, with differing expertise in analysis to reflect on their specific instructional partnerships and how they conduct preparation sessions.

LA coordinators and directors might use the PSOT for video analysis of the weekly preparation meetings and use the codes to categorize specific interactions between LAs and instructors, which would help in identifying different types of partnerships. In addition to providing a novel assessment tool that complements the more traditional diagnostic instruments, it provides data to implement more targeted professional development in an institution's LA Program to promote the maximum benefit of LAs.

An instructor might use the PSOT, or a shorter version of the PSOT, to gain insight on their partnership and help them determine ways to improve or change the partnership, if desired. For instance PSOT categories might help them think about a recent session and recognize that no time was spent on co-thinking about student understanding or course activity development. While this may not be something they value, it could be an oversight, or simply that they had not conceived of working with LAs in this way. The physics courses at CSU are fairly well structured with multiple components that emphasize active engagement. Because of this, it can be easy to overlook more collaborative ways to utilize LAs. One faculty member, after thinking about the types of partnerships and the PSOT, wanted to work with his LA more collaboratively than in previous semesters. He specifically commented in the mentor reflection that "this semester [my LA] led a couple of short lessons in class which I think went well - I'd like to do that...more" This reflection led to a change in practice.

The PSOT also highlights the many diverse ways LAs can be used to create effective, inclusive learning environments for students in LA supported classroom.

\section{ACKNOWLEDGEMENTS}

This work is supported by the National Science Foundation (DUE\#1524829), the Department of Education, the Illinois Space Grant Consortium, the Access Network, and the CSU Center for STEM Education and Research. Any opinions, findings, and conclusions expressed in this material are those of the authors and do not necessarily reflect the views of these agencies. The authors would like to thank the CSU LAs and faculty that allowed us to videotape their sessions. This work is Contribution No. LAA-50 of the International Learning Assistant Alliance.
[1] https://learningassistantalliance.org/ retrieved 7/1/2017

[2] V. Otero, S. Pollock, and N. Finkelstein, Am. J. Phys., 78, 11 (2010).

[3] M.S. Sabella, A.D. Robertson, A.G. Van Duzor, in Effective Practices in Preservice Physics Teacher Education, edited by E. Brewe and C. Sandifer (APS, College Park, MD, 2015), p. 117
[4] K.E. Gray and V. Otero, in AIP Conference Proceedings, edited by C. Henderson, M. Sabella, and L. Hsu, (AIP Publishing, NY, 2008), p. 123.

[5] M. S. Sabella, A. G. V. Duzor, and F. Davenport, in 2016 PERC Proceedings, edited by D. L. Jones, L. Ding, and A. Traxler (Sacramento, CA, 2016), p.288-291.

[6] E.W. Close, J. Conn, and H.G. Close, Physical Review Physics Education Research, 12, 1 (2016). 